\title{
Managing Complexity in Kuwaiti Organizations
}

\author{
Dr. Ahmad Assaf Alfadly \\ Faculty of Business Administration \\ Gulf University for Science \& Technology (GUST), Kuwait \\ Kuwait; Al-Faiha, block 9, street 91, villa 14 \\ Tel: 965-99-554-424 E-mail: dr_fadly@hotmail.com
}

\begin{abstract}
Joining collaborations and keeping relationships has become a most important concern for managers in most organizations. This change arises to a great extent due to the globalization of markets and the ongoing specialization of organizations, fostered by the possibilities of information technology and data communication. However, such a structural change requires adaptations by companies to fit the characteristics of industrial collaborations. In particular, the increasing complexity of collaborations in highly dynamic environments often is under estimated. In Kuwait, most organizations lack the analytical tools and associated operational bandwidth required to manage complexity. Reducing and managing complexity aims mostly at structuring organizations and implementing organizational changes. This article explores the implications of the emerging science of complexity for the management of organizations in Kuwait. It is not intended as an introduction to complexity thinking, but rather an attempt to consider how thinking "complexly" might affect the way in which managers do their jobs. In a sense, complexity thinking is about limits-limits to what we can know about our organizations. And if there are limits to what we can know, then there are limits to what we can achieve in a predetermined, planned way.
\end{abstract}

Keywords: Managing complexity, People and knowledge, Kuwaiti organization, Propose, Values

\section{Introduction}

The world has moved beyond the key triad markets. Internationalizing companies from developed and developing economies try to tap the benefits of globalization to an unprecedented degree and therefore face - as well as contribute to - the complexity of eroding boundaries. Sometimes abolishing boundaries creates new homogeneity in a larger area (e.g., the Euro currency), but mostly it doesn't. Various motives rank high on the list of possible drivers for foreign expansion: learning, spreading risk, gaining access to new customers, realizing economies of scale and scope, or optimizing one's value propositions with partners. But the road to the Promised Land turns out to be more demanding than expected, and complexity is the most common and pervasive challenge that arises. A core challenge to today's and tomorrow's Kuwaiti companies' complexity cannot be simplified, and it is not going away anytime soon. Managing complexity therefore must become a core competency of top executives and management in Kuwait. As a first step, it is crucial to understand what drives complexity (Colotla et al. 2008).

\section{Organization and Environment and complexity}

Today, industrial companies are challenged by a highly dynamic environment, which requires them to develop and manufacture products at a high level of flexibility and quality for low costs. Due to these challenges, companies are forced to specialize in order to both minimize product complexity and reduce production costs. At the same time, they have to intensify their collaborative activities in order to keep their level of service offering. More than a decade of intensified research in the field of enterprise networks reveals further reasons for an increasing amount of networks and collaborations, mostly emphasizing emerging market opportunities. Participating in collaborations and maintaining relationships within these thus has become a major concern for managers in industrial companies. This change requires companies to adapt in the way they manage their operations. In particular, the management in highly dynamic environments needs to address the increasing complexity of collaborative industrial structures. Globalization entailed a far-reaching erosion of boundaries and trade liberalizations allow for a substantially easier flow of goods, capital, people, and knowledge around the globe.

In our study, we've identified four major sources that interact to create today's environment. Each of these sources of complexity was created by the erosion of boundaries, but their effects differ from each other. 


\subsection{Diversity}

Kuwaiti organizations face a complex set of challenges characterized by diversity both inside and outside the organization - across every aspect of the business itself and its strategy drivers. Inside the organization, executives must manage and respond to more diversity in the (internationalizing) HR pool; more variety in the management systems; more variation in the means and ends, ranging from simple financial goals to a more comprehensive view; and different business models for different types of business units. Outside the organization, there is higher diversity: heterogeneous customer needs; differing cultural values; a plethora of stakeholders with different claims (investors; customers; employees' regulation; etc.); various political; economical; legal environments; and finally, competitors' differing strategies. Most firms today increasingly face each of these types of diversity. Managing these differences is not trivial, and reducing diversity often means being less responsive.

\subsection{Interdependence}

Companies must manage the effect of global interdependence to an unprecedented degree; everything is related to everything else, and the impact is felt more rapidly and pervasively. Value webs have replaced traditional value chains. Reputation, financial flows, value chain flows, top management, and corporate governance issues have reached advanced levels of interdependence. The less clear-cut the boundaries of a company become, the more it is exposed to impacts on the value chain flow through mistakes, frictions, reverse trends, or even shocks. Interdependence creates opportunities for globalization, but taking advantage of these opportunities raises difficult challenges.

\subsection{Ambiguity}

The business world today is characterized by too much information with less and less clarity on how to interpret and apply insights. Diverse accounting standards render financial figures ambiguous. Studies, scenarios, survey results, and reports become less reliable due to ever-increasing uncertainty. Many businesses find it more and more difficult to discover what their clear value drivers are. Are they image price-related services, privileged relationships, speed, knowledge, or something else? The cause-and-effect relationships become blurred.

\subsection{Flux}

As if these three complexity drivers were not enough, managers have to face yet another one: flux or change. Even if you arrive at temporary solutions regarding interdependence, diversity, and ambiguity for your specific company, industry, and/or personal situation, the situation can change the next day. Today's solutions may be outdated tomorrow.

\section{The repercussions}

Everything is diverse, and nothing is stable; everything is in "fast flux": interdependence is flowing in changing directions. The future no longer is the prolongation of past industry "breakpoints"; fundamentally altering the value proposition in industries occurs more rapidly. The variety of options could overwhelm traditional decision making as information often lacks clarity and is ambiguous. Multiple interpretations of the same facts are possible, depending on the perspective or cultural framework. Shared understanding cannot be assumed per se, whether inside or outside the organization. Thus, interdependence, diversity, and ambiguity - all in flux - are the building blocks of managerial complexity and explain why global companies often are perceived as the most complex organizations. Many people have tried to simplify complexity and contemporary management literature is misleading when trumpeting the success factor. Studies typically examine successful companies to see what managers "did" then conclude that all managers should do the same thing. As unpredictability makes us uncomfortable, delusions are created about performance as a voluntaristic matter of choice (companies can choose "to be great"); we like the certainty promised by these solutions. But in an interdependent world, much depends on contingencies, with no clear correction between input and output. Accountability of managers therefore has an arbitrary element: yes, managers are responsible, but results are influenced by factors beyond their control. Navigating through this complexity requires a different way of thinking, acting, and organizing than the typical "control" mentality. A long list of advantages lures companies into globalizing. Geographic expansion abroad offers the vast potential benefits of a much larger market arena; it spreads risks, scope, scaleand location-based cost advantages, and broader exposure to a variety of new product and process ideas. The practical consequence of complexity is that a managerial dilemma often shapes the decision-making process when there are two or more conflicting legitimate goals. Both cannot be achieved simultaneously with the given resources. Kuwaiti companies in the financial service industry set up competing distribution channels, but expect far-reaching cooperation across the company (shared services and product platforms) to reap economics of scale. 
In manufacturing, one ongoing dilemma is between global standardization and response to local market needs. Any required priority decision nevertheless results in ongoing tension. As dilemmas cannot be solved, they need to be managed continuously.

\section{Core processes and decentralized authority}

Core processes are those used by the entire company. These vary from business to business, but most managers know what is vital. In a consulting firm, core processes might be knowledge sharing and recruiting; in a heavy manufacturing firm, they might be capital budgeting and logistics; in a pharmaceuticals firm, they might be research and development and go-to-market processes. A firm's core processes always should be standardized (not necessarily centralized) and based on comprehensive accessible information platforms. As this imposes cost, one has to be very clear what is needed as core. Such processes might change over time, and more often than the business model or the core values. It therefore is important to erase old processes when introducing new ones. But only standardized processes generate the transparency key for accountability on levels further down the organization. With such transparency and accountability, therefore, decentralization is possible without the company breaking down into political silos and bickering fiefdoms. With decentralization consistent with core processes, local managers can engage complexity in the way most effective for them.

\section{Unpredictable situations an early awareness system}

Chaos is a degree of complexity in which few of the rules and drivers are understood. Compare it to a weather forecasting system: never completely right, but rarely completely wrong. And early awareness doesn't need sophisticated systems and much manpower. More than anything else, it is a mindset, a sensitivity that allows "weak signals" that indicate emerging change and foresight to be understood. To deal with complexity, identify the variables that create predictable outcomes when they're within a particular range and unpredictable outcomes when they are not. As one executive recently told us, "We track hurricanes. As long as they stay outside of this range, we don't pay much attention or put anything into action. But as soon as they hit inside this range, we rush to put our contingency plans into place." When facing complexity, managers need to identify which "hurricanes" they need to track and which levels or ranges should trigger contingency plans.

\section{Leadership}

Leading a complex organization requires an entirely different mindset. Hierarchy works if every level is doing something distinct and specific. However, due to the interdependence in complexity, this is impossible in today's organizations. By simplifying and clarifying vision and values, core processes and decentralization; and early awareness systems, hierarchy can be complemented by another "hierarchy" - the interdependent, networked organization in which every part reflects a different perspective of the whole and which is needed in today's global business world. The boss no longer needs to "tell" the team members exactly what to do, but rather depend on their initiative, creativity, and competence for success. The leadership and top management commitment is the most critical and crucial prerequisite for institutional success when problem arise. In addition; the management controls, arranges, does things right; leadership unleashes energy, sets the vision, does the right thing. Russel (2000) state that successful leaders anticipate change, vigorously exploit opportunities, motivate their followers to higher levels of productivity, correct poor performance and lead the institution toward its objectives.

\section{Mastering complexity in Kuwaiti organization}

We have not yet come across a Kuwaiti company that has mastered complexity in organization. Perhaps there are none; perhaps there never will be any. However, various sections of "Managing Complexity" point to several companies in Kuwait highlighting various aspects of managing complexity, or the effects of not managing it well The decade-long difficulties of Al-Ghanem - and to a lesser degree Al-Mulla - clearly have their roots in the long traditional control mode, leading to Al Ghanem's vast bureaucracy and a typical outcome: mediocre products due to risk aversion, mistrust of management (reflected in the high degree of unionization), high transaction costs, and slow response. An opposite example is Lulu Shopping Center, with a very clear value set (which now is challenged as it truly becomes a company all over the Middle East), a simpler model of core business processes, and standardized processes throughout the Middle East.

\section{Conclusion}

In conclusion, Kuwaiti organizations should understand the elements of simplifying and structuring in the management of complexity. The main challenge of today's and tomorrow's companies, complexity cannot be made easy, and it is not going away in the near future. Managing complexity must consequently become a core competency of top executives and management. Complexity is today frequently considered the latest business 
world it reflects a current common reality but not a lasting one. Even though no company may ever master complexity completely, it is possible, using these values, to at least find the way through complexity and even to take advantage of it.

\section{References}

Almany, Glen. (2004). Priority Effects of Coral Reef Fish Communities of the Great - Barrier Reef. Ecology, 85(10):2872-2880.

Ashby, W.R. An Introduction to Cybernetics, 9 (Chapman \& Hall: London) Bar-Yam, Y., et al., Complex Social Systems: Rising Complexity in Business Environments. Discussion paper, 2009 (Cambridge, MA: New England Complex Systems Institute).

Aswani, Shankar and Hamilton, Richard. (2004). Integrating Indigenous Ecological Knowledge and Customary Sea Tenure with Marine and Social Science for Conservation of Bumphead Parrotfish (Bolbometopon muricatum) in the Roviana Lagoon, Solomon Islands. Environmental Conservation, 31 (1):69-83.

Berkes, Fikret. (1999). Sacred Ecology: Traditional Ecological Knowledge and Resource Management. Philadelphia: Taylor and Francis.

Colotla, I., Shi, Y.-J., and Mike, J.G. (2009). Operation and Performance of International Manufacturing Networks. Int. J. Oper. Prod. Manage, 10, 1184.

Günther Schuh. (2008). Managing Complexity, Organizational Behavior and Human Performance. 88-121

Johnson, Michael P., Mason, Larry G., and Raven, Peter H. (1968). Ecological Parameters and Plant Species Diversity. American Naturalist, 102:297-306.

Jones, Geoffrey P., and Syms, Craig. (1998). Disturbance, Habitat Structure, and the Ecology of Fishes on Coral Reefs. Australian Journal of Ecology, 23:287-297.

Kathiresan, K. (2003). How Do Mangrove Forests Induce Sedimentation? Revista de Biologia Tropical, 51 (2):355-360.

Li, M., and Vitanyi, P. (2010). An Introduction to Kolmogorov Complexity and Its Applications. 2010 (New York: Springer).

Russel. (2000). "Customer Loyalty", Toward and integrated conceptual frame. Journal of the academy of marketing science, 22, pp 99-114.

Wegehaupt, P., Fuhrung von Produktionsnetzwerken. (2009). (RWTH Aachen: Aachen). Zhang, S., Electronic business in China. In 10th International Forum on Technology Management, Vienna, 2009 